\title{
THE IMPORTANCE OF PRICES IN TOURISM INDUSTRY - THE IMPACT OF GROWTH OF PRICES OF HOSPITALITY SERVICES ON THE DOMESTIC TOURISM DEMAND
}

\author{
Vuk Garača*1, Svetlana Vukosav*, Nevena Ćurčić*, Milan Bradić* \\ * University of Novi Sad, Faculty of Sciences, Departament of Geography, Tourism \\ and Hotel Management, Novi Sad
}

\begin{abstract}
Practice has shown that prices, an important economic factor, have a significant effect on the choice of tourist destination, i.e. they have a direct impact on the tourism demand and add to its elasticity. More often than not, the connection between the "prices in the hospitality industry and tourism demand dynamics" is not a simple one. Many various factors besides prices in the hospitality industry influence the decision on a tourism trip, rendering this connection very complex. The effect of prices on domestic tourism demand is particularly evident in developing countries with low avarage salaries. To be better able to objectively perceive the effect of price growth in the hospitality industry, in addition to the basic parameters (prices in hospitality services, domestic arrivals and overnight stays of domestic tourists), we also analysed the cost of life, average salaries and changes in the euro exhange rate. All the parameters are for Serbia and they cover a period of fifteen years, 2002-2016. The principal method used in the research is the statistical method of linear correlation analysis, where the linear correlation coefficient was taken as an indicator.
\end{abstract}

Keywords: prices, impact, basic and corrective factors, domestic tourism demand, hospitality industry.

1 Corresponding author: V. Garača, University of Novi Sad, Faculty of Sciences, Departament of Geography, Tourism and Hotel Management, Novi Sad;

e-mail: vuk.garaca@uns.dgt.ac.rs 


\section{Introduction}

Tourism is an economic activity that is largely dependent on the discretionary decisions of consumers, i.e. tourists. Consumers have a wide range of options to maximise their personal satisfaction (Bošković, Težak, Saftić, 2010). At the same time, consumers are constantly exposed to the economic and non-economic factors, which add to the distinct elasticity of tourism demand (Hanafiah, Harun, 2010; Tse, 2001). Economic factors are personal income, prices, exchange rate, etc. whilst non-economic factors include wars, natural disasters (fire, flood, earthquake), epidemics, environmental disasters, crises, etc. (Bakić, 2000).

Prices, as an economic factor, have a significant effect on tourist flow, i.e. have a direct impact on tourism demand and add to its elasticity (Crouch, 1992). On the one hand, the low-price strategy is normally used to attract more tourists, particularly to new tourist destinations whose promotion on the global tourism market has just started (Forsyth \& Dwyer, 2009). On the other hand, the highprice strategy is used where a mass tourism destination is to be turned into an exclusive destination. As a result, tourist numbers drop, which means that there is less pressure on the space, cultural and natural goods, whilst total spending is maintained or even increased (Tohidy, 2011). The relationship between the coefficient of elasticity of tourists (as consumers) and the increasing prices in the tourism sector, mainly in the hospitality industry, has been a subject of much research by both domestic and foreign scientists (Dwyer et al., 2000; Greenidge, 2001; Forsyth \& Dwyer, 2009).

The relationship between the prices in the hospitality industry and tourism demand is usually not simple and is dependent on a number of different factors that influence the decision on tourism trip (Morley, 1994; Dwyer, Frosyth, Rao, 2000). In fact, the relationship is quite complicated, especially where it concerns consumers in developing countries (Tkalec \& Vizek, 2016). To understand the effect of price growth in the hospitality industry on the domestic tourist flow in the context of the economic conditions in Serbia, in addition to analysing the basic parameters such as prices in the hospitality industry and elements of tourist flow (the number of domestic arrivals and nights spent by domestic tourists), the cost of living, average salary and the euro-dinar exchange rate in Serbia have also been taken into account. All the observed parameters cover a period of fifteen years, from 2002 to 2016.

The analyses of tourism flows in many countries show that the international to domestic arrivals ratio is between 1:5 and 1:6 (to one arrival in international tourism there are five to six arrivals in domestic tourism). In other words, in 2014, on 1 billion international arrivals there were 5-6 billion domestic arrivals (UNWTO Tourism Highlights, 2014 edition, 2015, 2). 


\section{Price as an instrument of business policy in the hospitality industry}

Meeting the needs of consumers is a prerequisite for the realisation of economic goals of any company. In this context, the price is regarded as an instrument in a company's business policy. The importance of prices in the economic theory and practice is demonstrated in the fact that all the important indicators of the functioning of economic operators are reflected in prices (Granovetter, 2005). A pricing policy is a guiding philosophy or course of action designed to influence and determine pricing decisions. It should provide an answer to the question: "How will price be used in the marketing mix?" (Rowley, 1997).

Pricing in the hospitality industry is influenced by external and internal factors. Internal factors include costs, organisation, working conditions. Cost is one of the key internal factors. However, its effect is limited as it determines only the price threshold (Kosar, 2002). The effects of external factors on pricing are more pronounced.

The strong influence of external factors is reflected in the complexity of operation of market mechanism. Market-related factors include a stage in a product's life cycle, price elasticity, competition, product and service differentiation (Morley, 1994; Mangion et al., 2005). Hospitality firms use various methods to set prices for their products. According Kotler (2005) hospitality managers often select different pricing approaches based on a combination of several factors, which include a firm's cost structure, competitors' prices and customer value perceptions of hospitality services. Cost-based pricing usually involves mark-up techniques using actual variable costs (product costs) at a desired product cost percentage. This pricing method is commonly used to set menu prices in restaurants. Alternatively, pricing methods based on customers' value perceptions of hospitality products exclude the consideration of costs and attempt to provide value by offering high quality at reasonable prices (Lewis and Shoemaker, 1997; Shoemaker et al., 2006).

Economic growth reflects in wage growth and in increased spending on tourism. However, in the times of economic recession and low salaries consumers will reduce their spending both on their basic and on auxiliary needs. Tourism demand is sensitive to the changes in prices in the hospitality industry. As one of the key elements in determining consumer preferences, prices are the means of competitive fight of receiving countries or destinations gaining in importance in the conditions of inflationary changes. It should be borne in mind that the demand sensitivity is linked both to travel motivation and to the type of service where the price correction is done. Thus, generally speaking, business trips have a distinct price elasticity. 
A stadium in a product life cycle has its specific application in tourism and, by that very fact, in the hospitality industry. From the aspect of service pricing, a product life cycle comprises the following stages: introduction, decline and revival. In the introduction stage, a decision is made to go with somewhat lower prices than those in renowned destinations and establishments with similar characteristics. The aim of the low-cost strategy as an instrument of business policy is to ensure the best possible market position for the new establishment. In the decline stage, however, where technical, technological and organisational business conditions have become outdated, the aim of the low-cost strategy is for the establishment to maintain old market positions. Finally, the revival stage, which follows technical and technological innovations and introduction of the latest business models, allows for certain increase in prices (Mazanec et al., 2007). Therefore, the structure of the newly formed selling prices should be examined, bearing in mind the increase in the cost due to the upgrading of the establishment.

Price elasticity is the range between the highest and the lowest selling prices. The specific characteristics of tourism and hospitality industries such as seasonally incongruous demand show seasonal differentiation of prices and, by that very fact, their elasticity. The range between the highest price in full season and the lowest price off-season can be quite significant. However, the timeframe during which the pressure of the demand allows for the highest selling prices is very short, so we cannot talk about great elasticity. Similarly, the limiting factors determining the price ceiling (general situation on the tourist market, prices in elite establishments in renowned tourist destinations, purchasing power driving certain segments of demand, etc.) should also be taken into consideration. As regards threshold price, it is, as we know, determined by operating costs. However, even where more substantial price reductions are possible off-season, their effects are limited by a number of factors (limited free time, habits, transport, climate, weakened recreational characteristics of natural resources etc.) (Djeri et al., 2014). In practice, the demand elasticity in relation to the prices is reflected in reduced tourist flow due to increased prices and/or in increased tourist flow due to reduced prices. The correlation between changes in prices in the hospitality industry and demand fluctuations as their consequence can be expressed quantitatively using the elasticity coefficient. A standard response of the demand to the changes in prices is either a growing or falling demand (tourist flow) proportionate to the falling or growing prices, respectively. However, in tourism, there are deviations from standard elasticity. Instead of tourist flow proportionately decreasing as a result of increased prices, it progresses. In other words, in tourism, tourist flow tends to decrease more rapidly than the prices tend to increase. Similarly, reduced prices do not usually lead to a proportionate increase in tourist flow but they cause its increase by degression. Faster decrease 
in tourist flow in comparison with an increase in prices, or slower increase in tourist flow in comparison with a decrease in prices, indicates greater demand sensitivity (elasticity) to the increase than to the decrease in prices (Kosar, 2002). Understandably so, considering that we are talking about about meeting the needs that are not of existential nature.

Competition is an important factor of pricing in tourism and in the hospitality industry. From a macroeconomic aspect, it is understandable that the placement of a country's offer on the international market is largely determined by the prices, primarily the prices of hotel services. This is especially evident in larger geographical areas with similar natural attractions (e.g. the Mediterranean) offering hotels of the similar standard quality. The substitution is easy due to the high consumer mobility. In such cases, where the prices are relatively uniform, a subjective understanding of the quality or the user's personal experience is based on non-material components of a hotel and tourism product. In other words, an individual offer carrier (an accommodation establishment or a company) is limited when it comes to independent pricing in the conditions of international competition. Naturally, the effects of competition are present on the local level as well. This means relatively small price ranges for the same type and category of establishment. Deviations from the prices of basic (hospitality) services in the establishments of the same type and category often come down to the differences in microlocation, transport network, condition of the equipment, additional amenities (Hung et al., 2010). Market-related factors indicate that pricing in hospitality industry is a complex and technical activity that that has to take into consideration all the specificities of tourism business. Bearing this in mind, other external factors should not be ignored, namely (Durbarry \& Sinclair, 20003): the spatial geographic criterion (the location of an establishment relative to the various types of tourist resources of various degrees of attraction); time criterion (when the services are used, the length of stay); various demand segmentation criteria (nationality, motivations for visiting, gender, age, etc.); position in the market chain; terms of payment; types of services, etc. Practice has shown that the effects of these factors come to light on a micro level, i.e. in the business environment of certain operators. Here, of course, the effects of these indicators are analysed on a macro level.

\section{Data collection and processing methods}

Several different methods were used in the research: (1) research of primary and secondary material, (2) statistical method, (3) synthetic, comparative, critical and descriptive methods. 


\section{Research of primary and secondary material}

Desk research is the analysis of primary and secondary material. This method was used to collect the statistics for domestic tourist flow (arrivals and nights spent) in Serbia. The statistics were collected from the official publications of the Serbian Statistical Office. In addition, a number of domestic and foreign scientific sources addressing the issues researched in this paper were used.

\section{Statistical method}

The statistics collected in the first stage (desk research) were processed using various statistical methods. Primarily, correlation analysis was used to examine the strength (intensity) of quantitative correlation of the observed phenomena. The linear (Pearson) correlation indicators are: coefficient of determination, coefficient of non-determination and correlation coefficient (Stojković, 2008). For the purposes of this paper only the correlation coefficient was used.

\section{Linear correlation coefficient}

Linear correlation coefficient $\left(\mathrm{r}_{12}\right)$ shows the strength (intensity) of linear correlation between variables $\mathrm{X} 1$ and $\mathrm{X} 2$, where:

$$
r_{12}= \pm \sqrt{r_{12}^{2}}
$$

The coefficient value is in the interval $-1 \leq r_{2} \leq 1$, where there is a statistical correlation between the observed phenomena. Where $r_{12}=0$, there is no correlation between variables $X_{1}$ and $X_{2}$, whilst where $r_{12}= \pm 1$, the correlation exists and it is functional. In statistical theory and practice there are two levels of correlation significant: 0.05 and 0.01 . We were used the second one.

\section{Other methods}

The following methods were also used in this paper: the synthetic method, where the conclusions were based on the systematic analysis of secondary material and the data obtained in field research; the comparative method, where the data found in the literature were compared with the data obtained in field research; the critical method, where we took a critical approach to the data from the literature and the data obtained in field research or in the statistical processing, and the descriptive method, where we tried to explain the results obtained. 


\section{Key elements of the research}

To have the best understanding of the intensity of the effect that prices in the hospitality industry have on domestic arrivals and overnight stays of domestic tourists, the following factors were taken into account: domestic arrivals, overnight stays of domestic tourists and prices in the hospitality industry. The factors that have an indirect effect on the observed correlation, namely the cost of living, average salaries and the euro exchange rate ${ }^{2}$ were also taken into account, as a corrective factor. The observed elements cover a continuous fiftteenyear period (2002-2016) for the territory of Serbia.

\section{Price index in hospitality industry}

The parameter "price index in the hospitality industry" indicates the changes in hospitality prices, i.e. in the prices of hotel and restaurant services, and as such may indicate structural changes in tourism or, compared with the euro exchange rate, the harmonisation of prices with the inflationary wave.

Table 1. Economic parameters which affect on domestic tourist flows

\begin{tabular}{|c|c|c|c|c|c|}
\hline Year & $\begin{array}{c}\text { Hospitality industry } \\
\text { price index } \\
\mathbf{( \% )}\end{array}$ & $\begin{array}{c}\text { Consumer } \\
\text { price index } \\
\mathbf{( \% )}\end{array}$ & $\begin{array}{c}\text { Average } \\
\text { salaries } \\
(\text { RSD) }\end{array}$ & $\begin{array}{c}\text { Average } \\
\text { salaries } \\
(\boldsymbol{€})\end{array}$ & $\begin{array}{c}\text { Euro exchange } \\
\text { rate (RSD) }\end{array}$ \\
\hline 2002 & 100.0 & 100.0 & 9208 & 152 & 60.6 \\
\hline 2003 & 110.5 & 113.2 & 11500 & 177 & 65.1 \\
\hline 2004 & 117.2 & 117.9 & 14108 & 194 & 72.6 \\
\hline 2005 & 136.4 & 134.9 & 17443 & 210 & 82.9 \\
\hline 2006 & 158.1 & 161.3 & 21707 & 258 & 84.2 \\
\hline 2007 & 164.7 & 167.3 & 27759 & 347 & 79.9 \\
\hline 2008 & 174.1 & 176.9 & 32746 & 402 & 81.5 \\
\hline 2009 & 185.0 & 188.7 & 31733 & 338 & 93.9 \\
\hline 2010 & 190.1 & 193.7 & 34142 & 330 & 103.5 \\
\hline 2011 & 194.3 & 197.6 & 37976 & 346 & 109.7 \\
\hline 2012 & 200.4 & 205.4 & 41377 & 366 & 113.1 \\
\hline 2013 & 206.3 & 213.2 & 43932 & 388 & 113.2 \\
\hline 2014 & 207.1 & 216.1 & 44530 & 380 & 117.3 \\
\hline 2015 & 208.6 & 218.0 & 44432 & 368 & 120.7 \\
\hline 2016 & 208.4 & 219.2 & 46097 & 374 & 123.1 \\
\hline
\end{tabular}

Source: Statistical Office of the Republic of Serbia, Statistical Yearbook, 2003-2017.

2 The exchange rate of the dinar is tied to the euro. 
Chain index was used in this paper, where the first year of the observed period (2002) was taken as a basis to which changes in the years that followed were successively added. This method was used because it was better suited for cross-analysis and because it best shows the tendencies in the observed phenomenon. Table 1 shows a constant increase in prices in the hospitality industry of $108.4 \%$ in $2002-2016$. The cross correlation analysis will show whether this is due to the harmonisation of prices with the euro exchange rate or a result of improved service quality.

\section{Consumer price index}

The consumer price index is a parameter that indicates changes in the prices of foodstuffs, consumer goods and services. It represents the amount of money needed to sustain a living, to satisfy existential needs. The cost of living increase may be an important factor in deciding whether to buy a tourist service because tourism is an auxiliary need and can be substituted easily with basic, existential needs. Thus, in addition to the analysis of hospitality industry prices, the important element of this paper is the analysis of the cost of living. Chain index was used in data processing, where the first year in the analysed period (2002) was used as a basis to which the changes in the years that followed were successively added. Table 4 indicates constant increase in the cost of living, reaching $119.2 \%$ in 2002-2016, which was 10.8\% higher than the increase in prices in the hospitality industry.

\section{Average salaries}

Average salary indirectly speaks of the economic development of a country, i.e. the purchasing power of its population. The data in Table 1 show that the salaries were growing slowly but constantly (400.6\% in RSD), and that the dinar to euro exchange rate went up as well (103.1\%) (Table 1). The question of the relativity of wage growth inevitably springs to mind as this is more about the nominal rather than the real wage growth. At the same time, wage growth is accompanied by the weakening of the dinar relative to the euro, resulting in a decrease rather than an increase in the purchasing power of the population. Salaries (expressed in euros) were growing from 2002 to 2008 (164.5\%), but they dropped by $17.9 \%$ in 2010 , which was reflected in the decrease in domestic tourist flow. Salaries increased by $146.1 \%$ in 2002-2016 - more than the euro exchange rate in the same period $(103.1 \%)$.

\section{Euro exchange rate}

The euro exchange rate reflects the value of the domestic currency, indirectly indicates inflation and is therefore the key corrective factor in this research. 
The data in Table 1 show that the exchange rate for the dinar against the euro was constantly going up, reaching over $103.1 \%$ in the observed period (20022016), which is somewhat higher than the price growth in the hospitality industry in the same period $(108.4 \%)$.

The prices in the hospitality industry are corrected against the euro and they follow every increase in the euro exchange rate. The prices in the hospitality industry grew faster than the average euro exchange rate in the observed period due to faster growing input prices and constant inflation. This is because a higher dinar exchange rate than the actual one is always calculated in the price in order to circumvent any sudden fluctuations and prevent any loss of profit from the sale of services in the hospitality industry.

\section{Domestic tourist flow}

Arrivals and nights spent are the most frequently observed indicators of tourism development in a country. It should be pointed out that nights spent is a much more complex information, which, more than the arrivals, reflects the intensity of tourism in an area. However, since they are best observed comparatively, they were both taken into consideration. The analysis of domestic arrivals and overnight stays of domestic tourists was particularly important for this paper because economic changes on the national level are in a direct causeand-effect relationship with the domestic tourist flow and their spending. In addition, the objective of the research is to show which forms of tourism (when it comes to domestic tourists) are affected by the prices in the hospitality industry most. In this regard, the subject matter of this analysis is domestic arrivals and overnight stays of domestic tourists by tourist destination (towns/cities, mountains and spas), as recorded by the Statistical Office of the Republic of Serbia. It is evident that the number of domestic tourists is in constant decline, rising mildly in 2007 and 2008 only to drop even more sharply immediately after (Table 2). In 2002-2014, domestic arrivals dropped by 38.7\%, while overnight stays were slightly higher $39.3 \%$. The drop in domestic arrivals and nights spent may have been caused by lower service quality or price growth in the hospitality industry and/or by a decline in the standard of living. The first of the three possible causes may be eliminated as the number of new and renovated 4-star and 5-star hotels is growing, as well as the number of apartments, hostels, campsites, increasing the diversity of offer $^{3}$, as well as the number of foreign tourists

3 On the one hand, the increase in the number of rooms and bed places in Serbia is a result of the reconstruction and refurbishment of many existing establishments following their privatisation, which meant significant investment in the buildings, the equipment and modern technology. On the other hand, new accommodation establishments have been opened e.g. hostels, special types of agritourism accommodation (salaši), etc. (Vukosav, Ćurčić, 2009). 
(310\% for the period 2002-2016) and overnight stays of foreign tourists (271\% for the period 2002-2016). (Statistical Office of the Republic of Serbia, Statistical Yearbook, 2003-2017). We are left with the price growth and/or the drop in the standard of living in Serbia.

Table 2. Domestic tourist arrivals and overnight stays ('000)

\begin{tabular}{|c|c|c|c|c|c|c|c|c|}
\hline \multirow{2}{*}{ Year } & \multicolumn{4}{|c|}{ Tourist arrivals } & \multicolumn{4}{c|}{ Overnight stays } \\
\cline { 2 - 9 } & Total & City & Mountain & Spa & Total & City & Mountain & Spa \\
\hline 2002 & 1897.6 & 1116.8 & 411.0 & 312.1 & 6468.5 & 2152.2 & 2048.7 & 2093.6 \\
\hline 2003 & 1658.7 & 965.2 & 355.4 & 290.9 & 5892.9 & 1918.8 & 1816.1 & 2008.6 \\
\hline 2004 & 1579.9 & 873.2 & 373.5 & 285.5 & 5791.6 & 1856.4 & 1748.1 & 2031.1 \\
\hline 2005 & 1535.8 & 820.2 & 379.4 & 285.6 & 5507.6 & 1724.5 & 1696.2 & 1947.5 \\
\hline 2006 & 1537.6 & 807.8 & 366.2 & 302.2 & 5577.3 & 1664.3 & 1651.1 & 2113.3 \\
\hline 2007 & 1610.5 & 776.5 & 409.5 & 359.1 & 5853.0 & 1639.3 & 1806.5 & 2243.5 \\
\hline 2008 & 1619.7 & 793.1 & 409.0 & 343.1 & 5935.2 & 1685.7 & 1776.3 & 2266.8 \\
\hline 2009 & 1373.4 & 693.0 & 349.8 & 334.2 & 5292.6 & 1334.3 & 1547.9 & 2189.6 \\
\hline 2010 & 1317.9 & 653.9 & 334.3 & 319.9 & 4961.4 & 1311.6 & 1337.8 & 2106.3 \\
\hline 2011 & 1304.4 & 552.1 & 355.1 & 341.6 & 5001.7 & 1219.5 & 1442.2 & 2176.6 \\
\hline 2012 & 1269.7 & 610.8 & 348.7 & 310.1 & 4688.5 & 1341.6 & 1445.4 & 1901.5 \\
\hline 2013 & 1270.7 & 601.5 & 338.3 & 350.3 & 4579.1 & 1446.4 & 1363.8 & 1953.3 \\
\hline 2014 & 1163.5 & 593.9 & 301.7 & 323.6 & 3925.2 & 1327.5 & 1196.8 & 1650.9 \\
\hline 2015 & 1304.9 & 646.9 & 366.8 & 348.5 & 4242.2 & 1437.1 & 1419.2 & 1623.8 \\
\hline 2016 & 1472.2 & 655.7 & 425.8 & 391.1 & 4794.7 & 1328.9 & 1641.4 & 1831.2 \\
\hline
\end{tabular}

Source: Statistical Office of the Republic of Serbia, Statistical Yearbook, 2003-2017.

When it comes to tourist flow by type, a sharp drop in the number of domestic arrivals $(46,8 \%)$ and overnights of domestic tourists (38.3\%) in the so-called city tourism over the period 2002-2014 is evident. Mountain tourism, another form of tourist flow, is specific as it largely depends on the solvency of the clients enjoying it. They come from higher or high-paying strata of population who, in addition to paying for their accommodation package, have to be able to spend part of their discretionary income on sports equipment and complementary tourist services. It should be pointed out that complementary tourist services are very expensive in Serbian ski resorts considering the average wage in Serbia. A drop in the number of this type of tourists is not as pronounced $(26.6 \%)$ as in city tourism but the number of overnight stays is $(41.6 \%)$. This means that while domestic tourists continue to go to domestic ski resorts in somewhat smaller numbers, they tend to shorten their stay in the mountains from 5 to 4 days (Table 2). 
A modest increase is recorded in domestic arrivals in Serbian spas (3.7\%) and decrease in overnight stays of domestic tourists (19.4\%) in the period (20022014). The distinct positive trends in spa tourism are partly due to better service quality and wider range of complementary tourist services (spas, wellness centres, aqua parks, swimming pools, sports courts/fields, entertainment, etc.), making the offer more attractive to wider consumer public rather than only to those who come to spas exlusively for medical treatment and/or healing. In this way, spas have considerably increased their tourism function.

The year-to-year decline in the domestic tourist revenue initiated the actions of the Government of the Republic of Serbia to take measures in order to stop the decline. In that sense, the Government launched the "Gift Voucher" programme to subsidize a domestic tourist with 5,000 RSD for spending the holidays in tourist destinations in Serbia. The programme had a positive impact since it increased the number of domestic tourists for $26.5 \%$, the number of overnight stays for $22.2 \%$ in the period 2014-2016. According to the data of the Ministry of trade, tourism and telecommunications, 46,000 citizens used the vouchers to pay for a part of their holiday cost spent a tourist destination in Serbia and realized over 400,000 overnight stays in 2016. Perceiving the diffeerence between the year 2015 and 2016, it may be concluded that the increase is a direct consequence of the programme designed and realized by the Ministry and the Government. Observing the main segments of tourism turnover in Serbia, the incentive mainly influenced the increase in mountain tourism, where the number of tourists increased for $29.1 \%$, and the number of overnight stays for $27.1 \%$. significant increase is perceived also in spa tourism with the increase of $17.3 \%$ in the number of tourist and $9.8 \%$ increase in the number of overnight stays. In urban tourism the increase of tourists was $9.4 \%$, whereas the number of overnight stays remained unchanged.

\section{Multidimensional data analysis}

A simultaneous and comparative analysis of the factors researched in this paper, namely the prices in hospitality industry and the elements of tourism flow, should indicate how the prices in hospitality industry, as the main element of a tourist product, influence the flow of domestic tourists in Serbia. Considering that the economic situation in Serbia is unstable and that the value of the domestic currency is on a slow but constant decline, in addition to the factors mentioned above, other parameters should be included corrective factors in the analysis as well, such as average salaries, consumer price indices and the euro exchange rate for the period 2002-2016. 
Table 3. The most significant correlation between the observed elements

\begin{tabular}{|c|c|c|}
\hline No. & Correlation & $\begin{array}{l}\text { The correlation } \\
\text { coefficient } \\
(\mathrm{r} 12)\end{array}$ \\
\hline 1 & The index of prices of hospitality services / Number of tourists & $-0,853^{* *}$ \\
\hline 2 & The index of prices of hospitality services / Nights & $-0,851^{* *}$ \\
\hline 3 & Price Index cost of living / Number of tourists & $-0,848^{* *}$ \\
\hline 4 & Price Index cost of living / Nights & $-0.861^{* *}$ \\
\hline 5 & Average salaries / Number of tourists & $-0,704^{* *}$ \\
\hline 6 & Average salaries / Number of nights & $-0,676^{* *}$ \\
\hline 7 & $\begin{array}{c}\text { The index of prices of hospitality services / Cost of living price } \\
\text { index }\end{array}$ & $0,999 * *$ \\
\hline 8 & The index of prices of hospitality services / Average salaries & $0,937^{* *}$ \\
\hline 9 & Price Index cost of living / Average salaries & $0,923^{* *}$ \\
\hline 10 & The index of prices of hospitality services / Euro & $0,944^{* *}$ \\
\hline 11 & Price Index cost of living / Euro & $0,950 * *$ \\
\hline 12 & Euro / Average salaries & $0,793^{* *}$ \\
\hline 13 & Euro / Number of tourists & $-0,874^{* *}$ \\
\hline 14 & Euro / Nights & $-0,935^{* *}$ \\
\hline 15 & The index of prices of hospitality services / Urban tourists & $-0,940^{* *}$ \\
\hline 16 & The index of prices of hospitality services / City Nights & $-0,927^{* *}$ \\
\hline 17 & The index of prices of hospitality services / Mountain tourists & $-0,341$ \\
\hline 18 & The index of prices of hospitality services / Mountain nights & $-0,820^{* *}$ \\
\hline 19 & The index of prices of hospitality services / Spa tourists & $0,674^{* *}$ \\
\hline 20 & The index of prices of hospitality services / Spa nights & 0,363 \\
\hline
\end{tabular}

** Correlation significant at 0,01 level

The parameters shown in the chart indicate that, generally speaking, the number of domestic tourists is falling whilst the prices in the hospitality industry and the cost of living are growing, all converging in 2007/2008, whilst the euro to dinar exchange rate and average salaries are showing somewhat different tendencies. However, more substantial conclusions cannot be based on charts alone, rendering it necessary to resort to the correlation analysis of the selected data. Table 3 shows the strength of correlations between the elements that have been selected for the purpose of this research as the most important and most influential ones, rendering it necessary to resort to the correlation analysis of the selected data. 
The first four correlations show that the growth in prices in the hospitality industry and the cost of living have a great impact $\left(r_{12}=-0.853 /-0.848\right.$ and $r_{12}=$ $-0.851 /-0.861$ ) on the number of domestic arrivals and the number of overnights of domestic tourists, and that the impact is inversely proportional and equally strong.

The correlation between the average salaries in Serbia and the number of domestic arrivals and overnights is significant $\left(r_{12}=-0.704 /-0.676\right)$, yet not particularly strong. However, it is evident that a consumer's salary or discretionary income has a bigger impact on the decision on the tourism trip than on the length of stay in a domestic tourist destination.

Correlations 7-11 are very important as they indicate economic trends in Serbia in 2002-2011, which can have an indirect effect on the domestic tourism flow in Serbia. The increase in the cost of living and the increase in prices in the hospitality industry are strongly connected, parallel processes $\left(\mathrm{r}_{12}=0.999\right)$, so they cannot be observed separately. Correlations 8 and 9 indicate much more clearly what the decrease in the domestic tourism flow in Serbia is essentially about. Average salaries in Serbia were better aligned with the growing cost of living than with the growing prices in the hospitality industry, which clearly indicates that tourism is an auxiliary need rather than a basic need of life. Therefore, price growth in the hospitality industry by $6.8 \%$ (difference: $r_{9}-r_{8}$ ) is evidently more likely to influence consumers to making a negative decision about a tourism trip than the increase in the cost of living is. This is supported by the fact that the cost of living and the prices in the hospitality industry are equally well and very solidly aligned with the growing value of the euro $\left(r_{12}=\right.$ 0.910/0.915).

Correlations 12, 13 and 14 are also interesting as they indicate that average salaries were aligned to the growing value of the euro $\left(r_{12}=0,793\right)$, but were still considerably higher when compared with the euro exchange rate, with the nominal average salary of 152 euros in 2002 and 374 euros in 2016, and that the increase in the euro exchange rate greatly influences the decrease in domestic arrivals $\left(r_{12}=-0.874\right)$ and overnight stays of domestic tourists $\left(r_{12}=-0.935\right)$.

The correlation analysis gave interesting results regarding some individual forms of tourism flow singled out as important for the tourism in Serbia (city tourism, mountain tourism and spa tourism). Correlation 15 shows that the growth in prices in the hospitality industry has the greatest effect on the city tourism flow and almost as great an effect on the decrease in the number of domestic tourists $\left(\mathrm{r}_{12}=-0.940\right)$ as well as on the decrease in the number of overnight stays of domestic tourists in cities $\left(r_{12}=-0.927\right)$. This means that city tourism is the most sensitive one and the most unstable one on the domestic tourist market. It is a known fact that city visits are very short, usually 1-2 days, that both city hotels and complementary tourist services in bigger towns and cities such as 
Belgrade, Novi Sad, Niš and Kragujevac are much more expensive than in small towns. All this results in an easy abandonment of the idea of city tourism and taking it off the priority list in exchange for longer, annual trips.

Going to the mountains makes a significant group of annual trips for many skiing aficionados. Skiing is one of expensive sports and those practicing it come from higher paying social strata, spending more money than an average domestic tourist does elsewhere. The correlation shows that price trends in the hospitality industry do not have as much of an influence on deciding to go skiing $\left(\mathrm{r}_{12}\right.$ $=-0.341)$ as they do on the length of stay in a ski resort $\left(r_{12}=-0.820\right)$. The latter classifies as strong influence.

Spa tourism in Serbia is specific as individuals (i.e. medical patients) who are referred to spas for treatment and/or rehabilitation by the Republic Health Insurance Fund are counted in the total number of arrivals. Their numbers are not negligible and they have a considerable impact on the results of this analysis, with positive and strong correlations $19\left(\mathrm{r}_{12}=0.674\right)$ and weak correlation $20\left(r_{12}=0.363\right)$, whilst price growth in the hospitality industry has effect, causing an increase in the number of domestic arrivals, but has not in the overnight stays of domestic tourists in Serbian spas, because of the influence of Republic Health Insurance Fund. This can be explained solely by the fact that state institutions fund the medical treatment, rehabilitation and stay of a significant number of patients in spas, having a positive effect on the strength of the observed correlation.

\section{Conslusion}

Taking into consideration all the elements analysed in this paper, it is evident that, in one way or another, they all influence domestic arrivals and overnights, i.e. a decision on tourism trip and on the length of stay at a tourist destination. However, prices in the hospitality industry, observed both directly and by analysing trends in average salaries, the cost of living and in the euro exchange rate in particular, are without a doubt strongly connected with the volume of tourism trips taken by domestic tourists. The prices in the hospitality industry and the cost of living have increased almost equally, by $108,1 / 119,2 \%$ in 2002-2014, the value of the euro around $103,1 \%$ and the salaries expressed in euros by $146,1 \%$, meaning that the prices in the hospitality industry grow faster than the euro exchange rate by $5,3 \%$. Using the same parameters, we can say that salaries were growing faster than both the euro $(43 \%)$ and the prices in the hospitality industry $(37,7 \%)$, which should mean that the purchasing power of the Serbian population is growing. However, it is evident from the continuous drop in domestic arrivals and overnight stays of domestic tourists that the real 
purchasing power of the population is on the decline and that the budget allocated for tourism is shrinking. This conclusion is based on correlations 13 and 14 , clearly showing that around $79,3 \%$ of the correlation can be explained by the fact that the drop in domestic arrivals and $93,5 \%$ in overnights in Serbia is due to the euro exchange rate going up. Since the prices in the hospitality industry were growing faster than the exchange rate for the euro by 5,3\%, and the purchasing power was in decline despite the nominal increase in salaries, it is obvious that price trends in the hospitality services have a significant impact $(85,3 \%)$ on domestic tourists' deciding whether to take a tourism trip and how long they will stay at their destinations in Serbia.

The impact of prices on the domestic tourism turnover is visible in the "Gift Voucher" programme of the Government of the Republic of Serbia and the Ministry of trade, tourism and telecommunications at the domestic tourism market. The institutions practically impacted the decrease of the average price of tourism services by giving subvention of 5,000 RSD per a domestic tourist for spending the holidays in tourist destinations in Serbia. It had a quick positive impact on domestic tourism revenue of 26.5\% (arrivals) and 22.2\% (overnight stays).

\section{References}

Bakić, O. (2000). Marketing u turizmu, Ekonomski fakultet: Beograd.

Bošković, D., Težak, A., \& Saftić, D. (2010). Media In Collecting Information

On Tourism Destinations And Sociodemographic Characteristics. Ekonomska istraživanja, 23(3), 111-120.

Crouch, G. (1992). Effect of income and price on international tourism, Annals of Tourism Research, 19(4), 643-664.

Djeri, L., Armenski, T., Jovanović, T., \& Dragin, A. (2014). How income influences the choice of tourism destination. Acta Oeconomica, 64 (2), 219-237.

Durbarry, R., \& Sinclair, M. T. (2003). Market shares analysis: The case of French tourism demand. Annals of Tourism Research, 30(4), 927-941.

Dwyer, L., Forsyth, P., \& Rao, P. (2000). The price competitiveness of travel and tourism: a comparison of 19 destinations. Tourism Management, 21, 9-22.

Fateme Tohidy, A. (2011). Economic Impacts of Tourism Industry. International Journal of Business and Management, 6(8), 206-215.

Forsyth, P. J., \& Dwyer, L. (2009). Tourism price competitiveness. In J.

Blanke, \& Chiesa, T. (Eds.), The Travel and Tourism Competitiveness Report 2009: Managing in a Time of Turbulence (pp. 77 - 90). Geneva Switzerland: World Economic Forum. 
Granovetter, M. (2005). The Impact of Social Structure on Economic Outcomest. Journal of Economic Perspectives, Vol. 19(1), 33-50.

Greenidge, K. (2001). FORECASTING TOURISM DEMAND An STM Approach. Annals of Tourism Research, 28(1), 98-112.

Hanafiah, H., \& Harun, F. (2010). Tourism Demand in Malaysia: A cross-sectional pool time-series analysis, International Journal of Trade, Economics and Finance, 1(1), 80-83.

Hung, W., Shang, J., \& Wang, F. (2010). Pricing determinants in the hotel industry: Quantile regression analysis. International Journal of Hospitality Management, 29(3), 378-384.

Kosar, Lj. (2002). Hotelijerstvo - teorija i praksa. Viša hotelijerska škola: Beograd.

Косар, Љ. (2012). Хотелијерство І. Висока хотелијерска школа струковних студија: Београд

Kotler, P., Bowen, J., \& Makens, J. (2005). Marketing for Hospitality and Tourism. Prentice-Hall, Upper Saddle River: New York.

Mangion, M.L., Durbarry, R., \& Sinclair, T. (2005). Tourism competitiveness: price and quality Tourism competitiveness: price and quality. Tourism Economics, 11(1), 45-68.

Mazanec, J., Wöber, K., \& Zins, A. (2007). Tourism Destination Competitiveness: From Definition to Explanation? Journal of Travel Research, 46(1), 86-95.

Morley, C. (1994). The use of CPI for tourism prices in demand modelling. Tourism Management, 15(5), 342-346.

Rowley, J. (1997). "Principles of price and pricing policy for the information marketplace". Library Review, 46(3), 179-189.

Schmidgall, R.S. (1997). Hospitality Industry Managerial Accounting. Educational Institute, American Hotel \& Motel Association, Lansing: MI.

Shoemaker, S., Lewis, R., \& Yesawich, P. (2006). Marketing Leadership in Hospitality and Tourism. Prentice-Hall, Upper Saddle River: New York.

Statistički godišnjak Republike Srbije, 2003-2017, Republički zavod za statistiku: Beograd.

Stojković, M. (2008). Statistički metodi u turizmu. Prirodno-matematički fakultet, Departman za geografiju, turizam i hotelijerstvo: Novi Sad.

Tkalec, M., \& Vizek, M. (2016), The price tag of tourism: does tourism activity increase the prices of goods and services?, Tourism Economics, 22 (1), 93-109.

Tse, R. (2001). Estimating the Impact of Economic Factors on Tourism: Evidence from Hong Kong, Tourism Economics, 7(3), 277-293.

Vukosav, S., \& Ćurčić, N. (2009). Promene u hotelijerstvu Vojvodine kao rezultat tranzicionih procesa. Zbornik radova Geografskog insituta "Jovan Cvijić" SANU, 59(1), 111-126. 